\title{
Soil eco-risk assessment using a simple earthworm (Eisenia fetida) qualitative avoidance test: A Romanian case study of five swine farm surroundings
}

\author{
C.L. Mosneang, I. Oprescu, E. Dumitrescu, F. Muselin, G.F. Borlea, G. David, and R.T. Cristina
}

\begin{abstract}
The assessment of soil contamination and natural self-purification dynamic soil processes can be accomplished by numerous eco-hygienic and sanitary means without additional pollution. Among these, sublethal earthworm avoidance behavior tests have proven to be most effective. The aim of this case study was to determine the soil pollution risk in five large swine farms in Romania by using an avoidance behavior test as a screening tool with adult specimens of the earthworm Eisenia fetida (ISO 17512-1:2008 qualitative test). Two

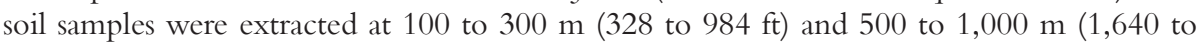
$3,280 \mathrm{ft})$ distance from each swine farm, and a single sample was taken at 1,300 $\mathrm{m}(4,265$ $\mathrm{ft})$ distance. The results were analyzed statistically using the Anderson-Darling Normality Test (NIST/SEMATECH) and have shown that out of the 11 soil samples, the earthworms strongly avoided $(p \leq 0.005) 4$ of them, confirming a potential eco-risk. The majority of the samples avoided by the specimens were collected at the 500 to $1,000 \mathrm{~m}$ range. However, the soil sample taken 1,300 $\mathrm{m}$ away from the farm showed that, at this distance, the soil had no sign of contaminants, as earthworms preferred the testing soil to the reference sample. In our opinion, this simple assessment, which produces fast and accurate results, should be included in a battery of tests as a helpful early qualitative screening tool in soil contamination assessment procedures to reveal a potential eco-risk.
\end{abstract}

Key words: earthworm avoidance test—soil pollution—swine units survey

The presence of increasing amounts of pollutants in ecosystems is no longer a novelty, and as there are numerous publications on this subject, there is an increasing awareness about the real impact of the swine industry on the environment, especially in regions with dense animal populations. Although large numbers of potential pollutants may not have been inventoried yet, it is already known that intensive swine farming can negatively impact the environment in multiple ways. Swine slurry applied to agricultural soils contributes to improved soil quality since it provides organic matter and nutrients. Among these, nitrogenous substances play a significant role as a constant fertilization source. The effluent also serves as fertigation, supplying nutrients and water from livestock farms. However, nutrient recycling practices
2000; Cools 2001; Feisthauer 2003; Lukkari 2004; Zhou et al. 2007; Lanno et al. 2004; Fründ et al. 2009; Natal-da-Luz et al. 2009; Bartlett et al. 2010).

It is known that earthworms display an avoidance behavior in response to the presence of sublethal concentrations of numerous chemical substances or microorganisms with ecological relevance to the soil (Murry and Hinckley 1992; Farenhorst et al. 2000; Shin and Kim 2001; Lanno et al. 2004; Udovic and Lestan 2010; Wang et al. 2012).

Bartlett et al. (2010) demonstrated the importance of using tests on oligochaetes, reviewing a great number of specific testing methods. In contrast, De Sousa et al. (2011) observed (after testing cypermethrine) that neither the pollutant, nor the concentration or the different characteristics of the soil, influenced the avoidance behavior of the earthworms (Bartlett et al. 2010; De Sousa et al. 2011). In a comprehensive assay, Wang et al. (2012) tested 24 insecticides on Eisenia fet$i d a$, demonstrating that toxicity depends on the category of chemical substances and on the testing procedures (Wang et al. 2012).

The avoidance studies carried out so far have shown that a particularly suitable species of oligochaetes for ecotoxicity studies is Eisenia fetida. This species has the characteristic of not digging too deep (10 to $20 \mathrm{~cm}$

Crina Laura Mosneang is a postdoc student in the Department of Pharmacology and Pharmacy, Faculty of Veterinary Medicine, Banat's University of Agriculture and Veterinary Medicine "King Michael I of Romania" from Timișoara (BUAVMT), Timisoara, Romania. Ion Oprescu is a professor and head of the Department of Ecology, Faculty of Veterinary Medicine, BUAVMT "King Michael I of Romania" from Timișoara, Romania. Eugenia Dumitrescu is a lecturer in the Department of Pharmacology and Pharmacy, Faculty of Veterinary Medicine, BUAVMT "King Michael I of Romania" from Timișoara, Romania. Florin Muselin is a lecturer in the Department of Toxicology, Faculty of Veterinary Medicine, BUAVMT "King Michael I of Romania" from Timișoara, Romania. Gheorghe Florian Borlea is a professor in the Biologic Agriculture Department, Faculty of Agriculture, BUAVMT "King Michael I of Romania" from Timișoara, Romania. Gheorghe David is a professor and head of the Biologic Agriculture Department, Faculty of Agriculture, BUAVMT "King Michael I of Romania" from Timișoara, Romania. Romeo Teodor Cristina is a professor and head of the Department of Pharmacology and Pharmacy, Faculty of Veterinary Medicine, BUAVMT "King Michael I of Romania" from Timișoara, Romania. 
[6 to 8 in]) and prefers soils rich in organic matter from decomposed plant residues or animal manure. This is the reason why we chose this species for the ecotoxicity analysis of areas surrounding swine farms. One of the first detailed studies testing the effects of various chemicals on earthworms was performed by Edwards and Bohlen in 1992, revealing the need for the standardization of eco-pollution assessment methods (Edwards and Bohlen 1992).

By creating and using original devices, it was demonstrated that earthworms avoid contaminated soils. For example, Yeardley et al. (1996) found that E. andrei/fetida avoided sublethal concentrations of chemical pollutants in soils after a short exposure of one to two days (Yeardley 1996; Stephenson 1998; Feisthauer 2003). In the case of Eisenia fetida, Yeardley (1996) noted clear avoidance responses 48 hours after testing began (Yeardley et al. 1996). Over the years, other exposure periods have been tested, ranging between 24 and 72 hours, in studies conducted in 2001 and 2003, that proved the avoidance behavior of earthworms in soil contaminated by organic pollutants at concentrations similar to those that have a visible impact in chronic toxicity tests, for 56 days (Stephenson et al. 1998; Hund-Rinke and Wiechering 2001; Hund-Rinke et al. 2003).

Summarizing our review of prior published information, we can conclude that avoidance tests offer a good practical advantage, namely a short duration (usually 48 hours) and a high sensitivity, providing behavioral responses to pollutant sublethal/toxic concentrations. Also, the ease of use and reproducibility of these tests can be useful from an ecological perspective when performed in accordance with standard acute toxicity tests, such as those that evaluate the lethal/sublethal effects on the growth and reproduction of these organisms (OECD 1984; Gunadi and Edwards 2003; Natal-da-Luz et al. 2004; Environment Canada 2004; Loureiro et al. 2005; ISO 2008; Gibbs et al. 2009).

Our eco-risk approach consisted of observing the effects of swine farm effluents on soil quality by evaluating the avoidance behavior of adult earthworm E. fetida (ISO 17512$1: 2008)$. Sublethal tests were performed for soil samples provided from the vicinity of five large farms in Timis County, Romania, with the aim of providing a simple and potentially helpful eco-toxicological qualitative methodology to an eco-hazard assessment.

\section{Figure 1}

The experimental device used $(T=$ test soil sample; $C=$ control soil sample).

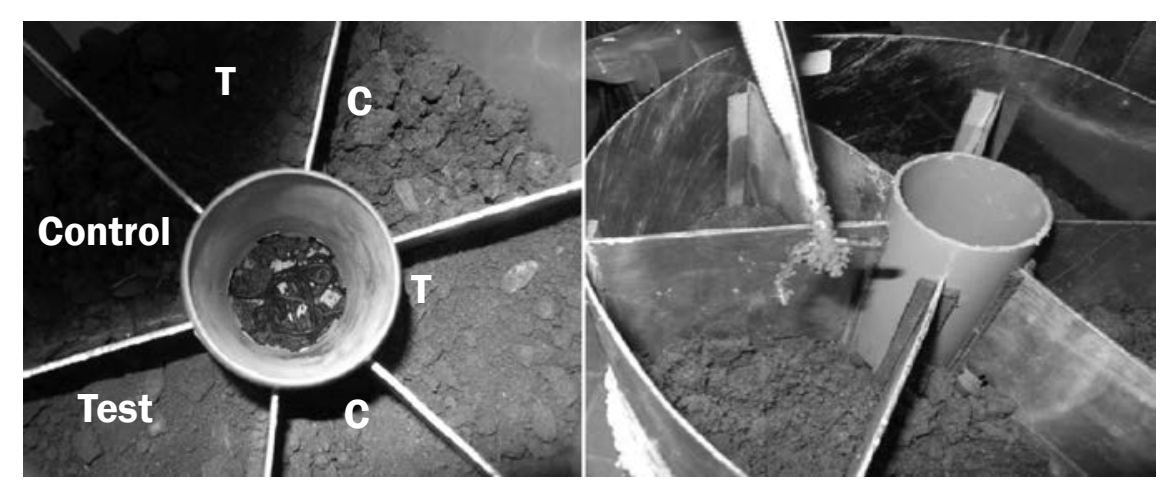

\section{Materials and Methods}

Testing Device and Methodology. The study apparatus was assembled in accordance with the device described by Yardley (1996) and improved by Stephenson (1998). Each device consisted of a circular container divided in six equal compartments where the different soil samples are placed, each one connected to a central circular chamber where the specimens are introduced at the beginning of the experiment (Yeardley 1996; Stephenson 1998). The only differences between the original device and our own are related to material composition; the outer circular container was made of colorless polyester, the partitioned perforated dividers were glued to the circular container, and a ceramic plate was used for the base (figure 1).

According to ISO 17512-1:2008 and EPS 1/RM/43/2004 methodology described tests, for each test and reference (control) soil sample, 100 earthworms (E. fetida from laboratory culture) were used, 10 for each test, which was repeated twice in five test devices, each containing three compartments filled with test soil and three with reference unpolluted soil, (C samples). The test and reference soil samples were well homogenized, with equal amounts of soil being introduced in the six compartments of the test apparatus. These were filled with different soil substrates to a height of approximately $15 \mathrm{~cm}$ (6 in). The soil layering was done in $3 \mathrm{~cm}$ (1.18 in) layers, which were compacted with the fist to $1.4 \mathrm{~g} \mathrm{~cm}^{-3}$ (Fründ et al. 2009).

Before commencing the test, the earthworms were individually weighed for each test unit and repetition. For the assessments, sexually mature Eisenia fetida earthworms, weighing between 250 and $800 \mathrm{mg}(0.008$ and 0.028 $\mathrm{oz})$, with a clearly visible clitella were used.
Knowing their humidity preference $(70 \%$ to $80 \%$ ), an important issue for using this species of earthworm, is to maintain the $70 \%$ water holding capacity (WHC) in the compartmentalized soil samples. This was accomplished by moistening each compartment at regular intervals according to the WHC of the tested soil subtypes in our assay, following the instructions of Fründ et al. (2009).

After the desired water content was reached, the earthworms were introduced in the central chamber of the testing device in order for them to select a direction of migration to their desired soil. The test duration was 48 hours, during which the soil samples were not renewed to avoid disturbing the activity of the oligochaetes. A temperature of $20^{\circ} \mathrm{C} \pm 2^{\circ} \mathrm{C}\left(68^{\circ} \mathrm{F} \pm 3.6^{\circ} \mathrm{F}\right)$ and a $16: 8$ hours per day photoperiod (light:dark ratio) were maintained throughout the assay.

Studied Swine Units. The samples used in the assays were extracted from several different locations near swine farms (from Unit 1 to Unit 5) in Timis County, Romania (figure 2). These specific units were selected for their high pollution potential and for the fact that they are located in close vicinity of the main rivers of the county.

Data collected at soil sampling of the swine units included GPS coordinates, hour of sampling, ambient temperature, atmospheric pressure and weather conditions, relative humidity, soil subtype, and general characteristics (appearance, composition, texture, etc.) in the sampling section after SRTS-2012 (T,ărău 2013). Also the values of nitrates $\left(\mathrm{NO}_{3}\right)$, phosphates $\left(\mathrm{PO}_{4}\right)$, and chlorides for each sample were determined.

The soil samples were collected from a depth of no less than 15 to $20 \mathrm{~cm}$ (6 to 8 in) from the vicinity of five large swine units. Two extraction spots were chosen, located at 


\section{Figure 2}

Geographical location of the five studied swine units (Harta judetului Timis 2015).

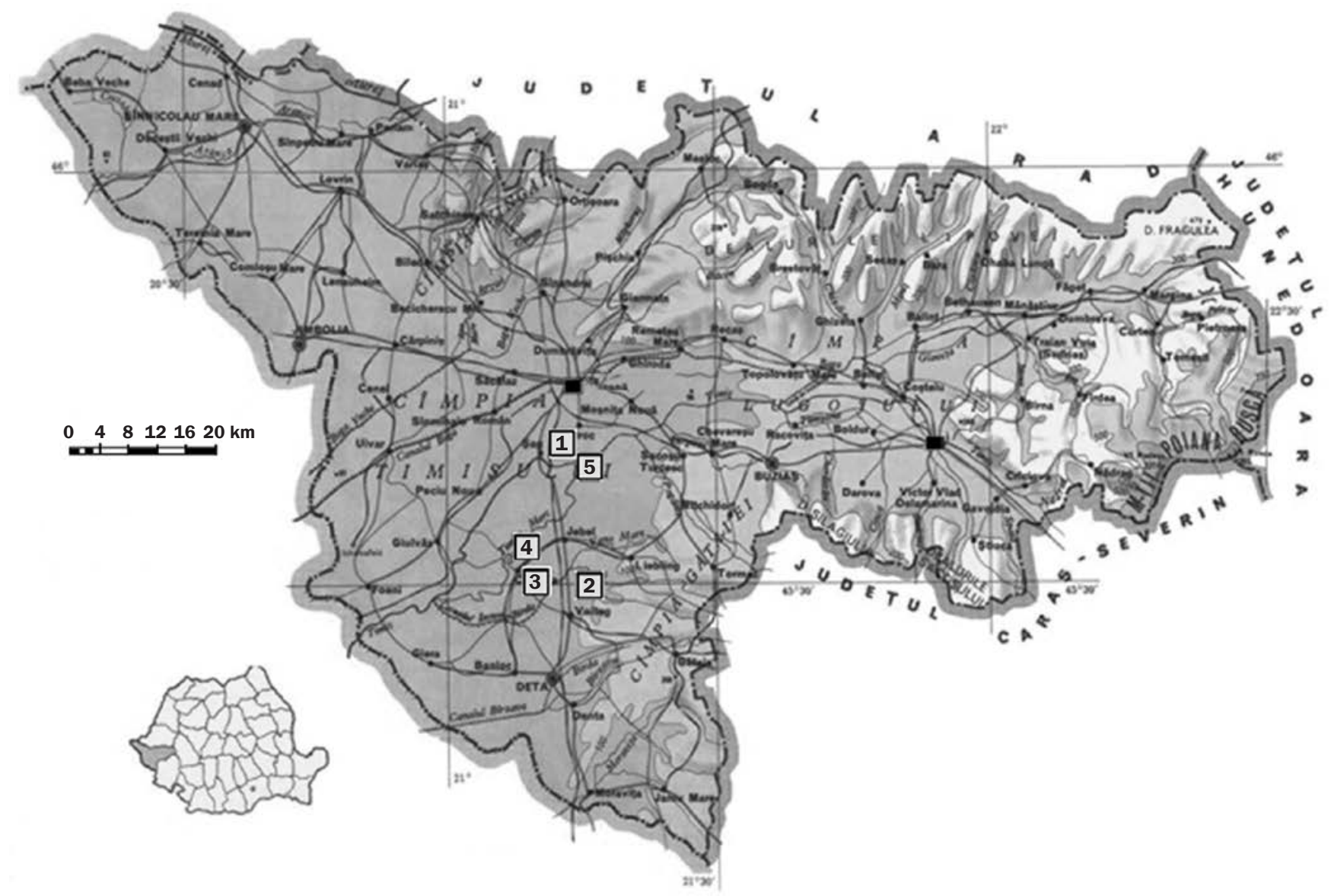

100 to $300 \mathrm{~m}(328$ to $984 \mathrm{ft}$; sample $a)$ and 500 to $1,000 \mathrm{~m}(1,640$ to $3,280 \mathrm{ft}$; sample $b)$ distance from the farms. An additional sample $(c)$ was collected from a distance greater than $1,000 \mathrm{~m}$, about $1,300 \mathrm{~m}(4,265 \mathrm{ft})$ from the farm. Soil samples from the corresponding farms are noted as Units 1, 2, 3, 4, and 5 (table 1 and figure 2).

The results were compared to those from the soil samples considered to have zero risk of swine manure pollution (control), taken under the same conditions from a large public park in the city of Timișoara. After sampling, all soil samples were placed in hermetically sealed polyethylene bags and stored at $-20^{\circ} \mathrm{C}\left(-4^{\circ} \mathrm{F}\right)$ until the measurements took place.

Statistics. The results were analyzed using an Anderson-Darling normality test (NIST/SEMATECH), where values up to $p \geq 0.05$ were considered normal; values of $p<0.05$ were considered not normal and statistically significant. The Anderson-Darling test makes use of specific distribution in calculating critical values and was, therefore, considered the most suitable for the current research situation.

\section{Results and Discussion}

During the tests, no changes were observed in the behavior of the earthworms, such as their presence on the surface of the soil at the end of the test. By comparing the ecotoxicity results from Unit 1, it was found that earthworms have avoided the soil taken from a distance of 100 to $300 \mathrm{~m}$ (328 to $984 \mathrm{ft}$ ) from the swine farm. A statistical analysis using the Anderson-Darling normality test of the samples from swine Unit 1 revealed values of $p<$ 0.005 (for sample $a$ ) and $p=0.044$ (for sample b). By comparing the values obtained from samples from Unit 2, it was found statistically that $p=0.073$ for $a$ samples and $p=0.01$ for $b$ samples; the situation was considered to be normal. Analyzing the ecotoxicity for Unit 3 samples, it was found that the earthworms have avoided the soil taken from a distance of 500 to $1,000 \mathrm{~m}(1,640$ to $3,280 \mathrm{ft})$ from the swine farm, with $p$ values for sample $b(p$ $<0.005)$ compared to $p=0.015$ for sample a. In the case of swine Unit 4 , where the soil samples were taken from a distance of 100

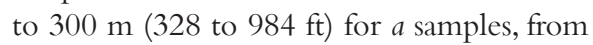
500 to $1,000 \mathrm{~m}$ for $b$ samples, and over 1,000 $\mathrm{m}$ for $c$ samples, the statistical certain values for earthworms that avoided soil from Unit 4 occurred in samples 500 to $1,000 \mathrm{~m}$ away $(p$ $<0.005)$ for $b$ samples. Comparing the averages of the samples from Unit 5, it was found that the earthworms particularly avoided the soil taken from a distance of 500 to $1,000 \mathrm{~m}$ from the farm. The statistical data obtained from the Unit 5 samples revealed a $p=0.05$ for a samples and $p<0.005$ for the $b$ samples taken 500 to $1,000 \mathrm{~m}$ away from the farm.

After analyzing all the results, we can be certain that the earthworms avoided the soils of the samples 1a (Unit 1), 3b (Unit 3), 4b (Unit 4), and 5b (Unit 5). According to our 


\section{Table 1}

Soil sample locations and selected parameters.

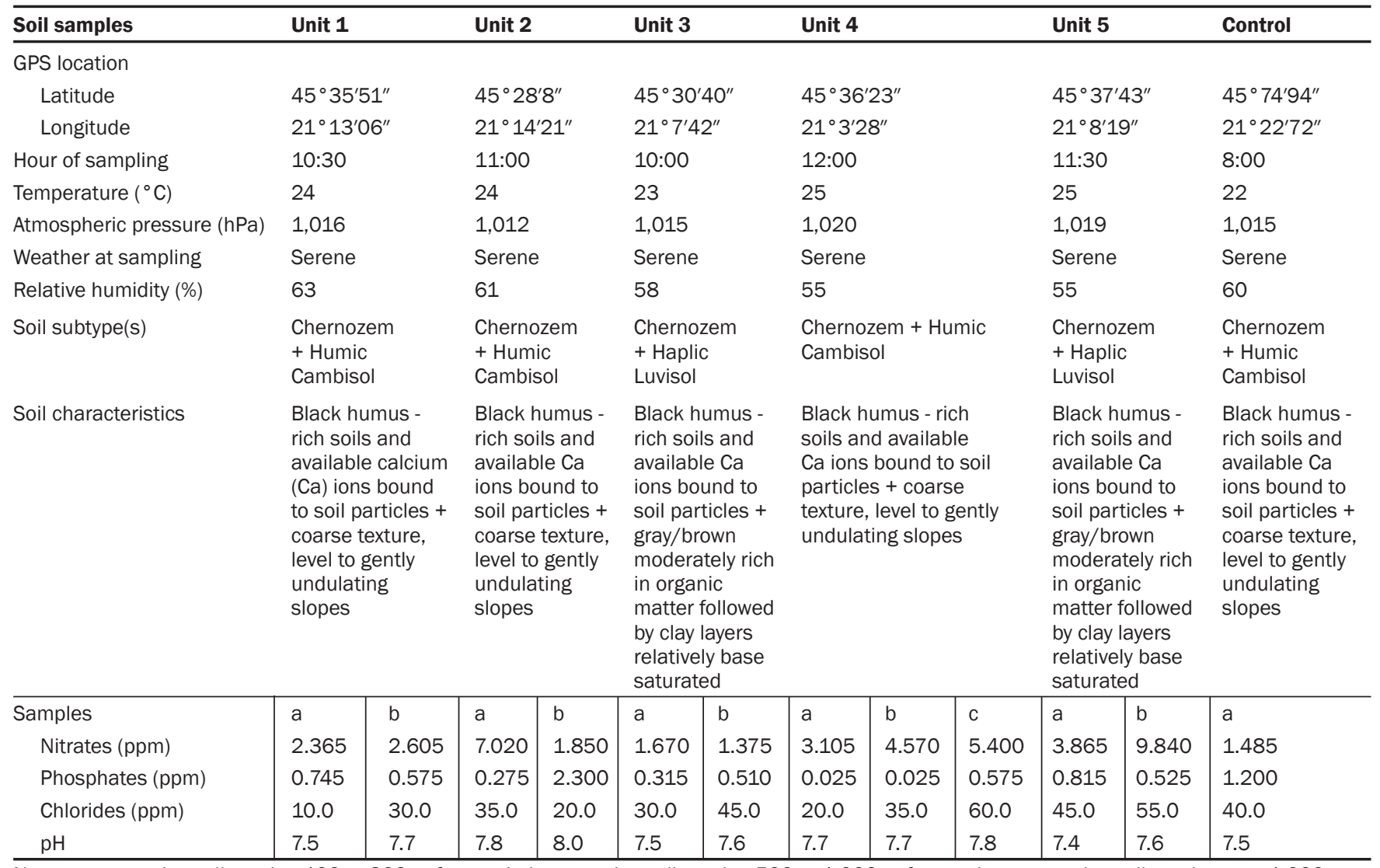

Notes: $\mathrm{a}=$ samples collected to 100 to $300 \mathrm{~m}$ from unit. $\mathrm{b}=$ samples collected to 500 to $1,000 \mathrm{~m}$ from unit. $\mathrm{c}=$ samples collected to over $1,000 \mathrm{~m}$ from unit.

tests, the earthworms did not avoid samples 1b (Unit 1); 2a and 2b (Unit 2); 3a (Unit 3); 4a (Unit 4); and 5a (Unit 5), taken generally at 100 to $300 \mathrm{~m}$ (328 to $984 \mathrm{ft})$ distance from the swine farms. The soil taken from Unit 4 , at a distance of $1,300 \mathrm{~m}(4,265 \mathrm{ft})$, was also preferred by earthworms. The comparative statistical analysis of E. fetida individuals avoiding potentially polluted soils is presented in figure 3 .

Tests of polluted soil avoidance are important for ecotoxicological assessment practice because of the many advantages they offer: they can be easily performed in a short time and at reduced costs and the results can be used to assess pollution of soil samples taken from areas with uncertain ecotoxicological conditions.

Our observations are consistent with those of Natal-da-Luz et al. (2004) who stated that earthworm population density decreases with the increase of pollutant concentration, as well as those of Feisthauer (2003), who found that the advantage of avoidance tests is the fact that they are a fast and economical alternative to breeding tests, and may set the stage for the initial screening of potentially contaminated soils. Also, our observations confirmed that the avoidance behavior parameter is a key factor, perfectly measurable as a statistical value, being in accordance with Loureiro et al. (2005), who demonstrated that the behavioral parameter is equally or even more sensitive than some sublethal parameters (e.g., breeding and somatic growth).

In our opinion, the earthworm avoidance test has a high enough specificity to generate definite qualitative results if correctly performed and could be used to determine the presence of an ecotoxic threat, providing valuable data about the extent of the pollution. In this regard, the statistical test we used, namely Anderson-Darling, an enhanced version of the Kolmogorov-Smirnov test, was applicable to this type of testing and has also been reviewed and recommended by other authors (Romeu 2000; Jäntschi and Bolboac`a 2009).

\section{Summary and Conclusions}

The results obtained after testing the soil samples that were considered to hold a potential risk of pollution have shown that out of 11 sampling locations, E. fetida adult earthworms avoided soils from four locations respectively: Unit 1(a), Unit 3(b), Unit 4(b), and Unit $5(b)$; the majority of avoided soils were those sampled at 500 to $1,000 \mathrm{~m}(1,640$ to $3,280 \mathrm{ft}$ ) distance from swine farms. In the case of the soil sample taken at over 1,000 m distance from the farm $(1,300 \mathrm{~m}[4,265 \mathrm{ft}])$, it has been demonstrated that soil ecotoxicity at this distance was no longer a threat to earthworms, which preferred the testing soil to the reference sample. In our opinion, this simple assessment should be included in a battery of tests used to indicate potential eco-risks because it can provide a fast and sufficiently accurate early screening tool in soil contamination. 


\section{Figure 3}

Eisenia fetida avoidance behavior statistical analysis in the tested soils/sample (a) No. 1a /Unit 1, (b) 3b/Unit 3, (c) 4b/Unit 4, and (d) 5b/Unit 5 , respectively.

(a)

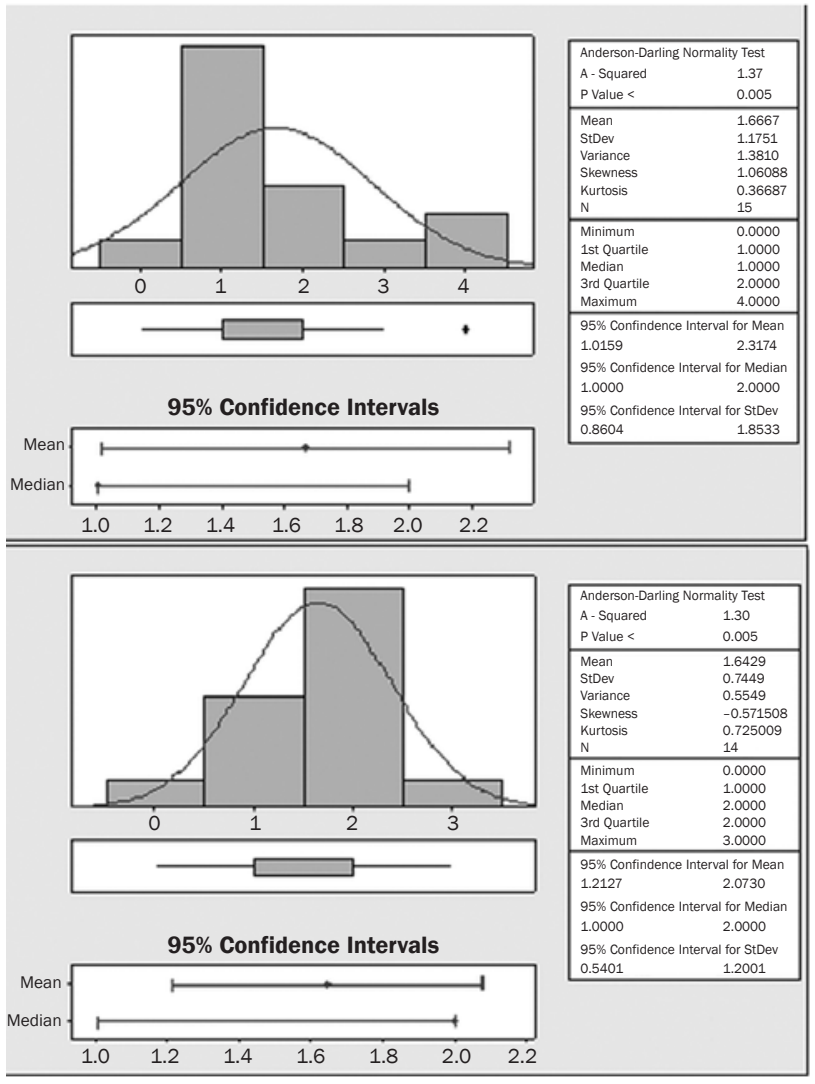

(b)

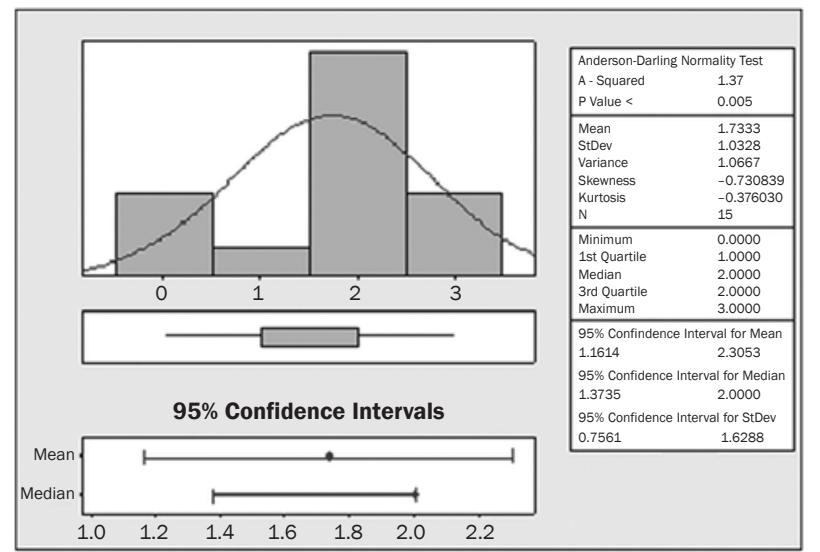

(d)

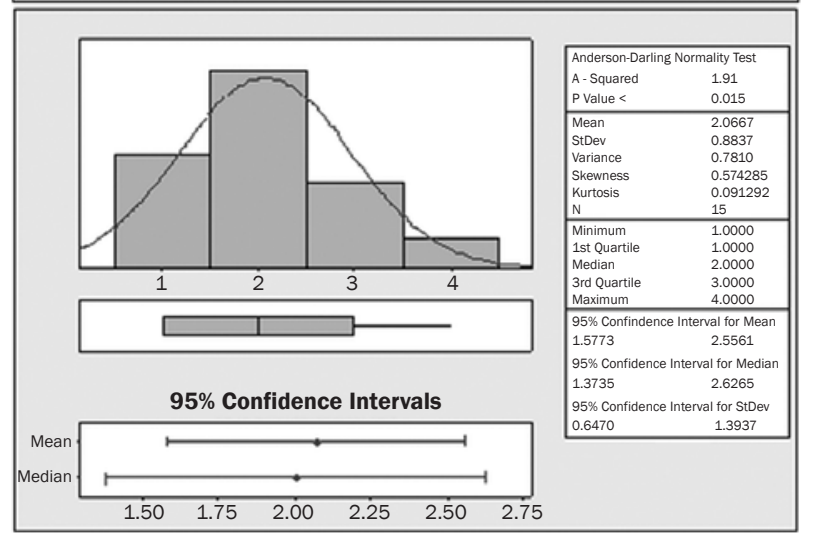

\section{Acknowledgements}

This work was co-financed from the European Social Fund through Sectorial Operational Programme Human Resources Development 2007-2013, POSDRU/159/1.5/S/132765.

\section{References}

Asman, W.A.H. 1995. Ammonia and ammonium in the atmosphere: Present knowledge and recommendations for further research. In Proceedings of a Speciality Conference. Acid Rain Research: Do We Have Enough Answers? Hertogenbosch, Netherlands, October 10-12, 1994, 55-70. Amsterdam, Netherlands: Elsevier Science B.V.

Bartlett, M.D., M.J.I. Briones, R. Neilson, O. Schmidt, D. Spurgeon, and R.E. Creamer. 2010. A critical review of current methods in earthworm ecology: From individuals to populations. European Journal of Soil Biology 46(2):67-73.

Bernal, M.P., and H. Kirchmann. 1992. Carbon and nitrogen mineralization and ammonia volatilization from fresh, aerobically and anaerobically treated pig manure during incubation with soil. Biology and Fertility of Soils 13(3):135-141.

Bratanov, V. 1979. Manure as a factor for environmental pollution with microorganisms and parasites. In Veterinary - Hygienic Aspects of Environmental
Pollution, ed. J. Karadjov, 50-227. Sofia, Bulgaria: Zemizdat Bulgaria.

Cools, D. 2001. Manure-derived antibiotic resistant bacteria: Survival in soil and contamination of crop roots. $\mathrm{PhD}$ dissertation, Katholieke Universiteit Leuven, Belgium.

Daumer, M.L., F. Beline, F. Guiziou, and J. Martinez. 2001. Phosphate recovery following biological aerobic treatment of pig slurry. Cemagref, Rennes, France. http://www.nhm.ac.uk/research-curation/projects/ phosphate-recovery/Nordwijkerhout/Daumer.doc.

De Sousa, A.P., and M.M. De Andrea. 2011. Earthworm (Eisenia andrei) avoidance of soils treated with cypermethrin. Sensors (Basel) 11:11056-11063.

Doran, J.W., and M.R. Zeiss. 2000. Soil health and sustainability: Managing the biotic component of soil quality. Applied Soil Ecology 15(1):3-11.

Edwards, C.A., and P.J. Bohlen. 1992. The effects of toxic chemicals on earthworms. Reviews of Environmental Contamination and Toxicology 125:23-99.

Environment Canada. 2004. EPS 1/RM/43. Biological test method. Tests for toxicity of contaminated soil to earthworms (Eisenia andrei, Eisenia fetida, or Lumbricus terrestris). Environment Canada, Environmental Technology Centre. http://publications.gc.ca/site/ eng/437659/publication.html.
Farenhorst, A., E. Topp, B.T. Bowman, and A.D. Tomlin. 2000. Earthworm burrowing and feeding activity and the potential for atrazine transport by preferential flow. Soil Biology and Biochemistry 32(4):479-488.

Feisthauer, N. 2003. Using earthworm behavior to assess contaminated soil. Environmental Science \& Engineering Magazine. http://www.esemag.com/ archive/0503/earthworm.html.

Frate, C. 2008. Nitrogen Transformations in Soil. Tulare, CA: University of California Cooperative Extension. http://cdrf.org/wp-content/uploads/2012/01/11.7_ Nitrogen_Transformations-final.pdf.

Fründ, H.C., H. Wallrabenstein, S. Leißner, and R. Blohm. 2009. Developing a soil quality test with 2D terraria and Aporrectodea caliginosa. Workshop Kommission III der Deutschen Bodenkundlichen Gesellschaft "Experimenting with Earthworms." Trier, Germany: Veranstalter: Kommission III der DBG 20-21.03.2009. http://eprints.dbges.de/90/2/Fruend_ TrierDBG_2009.pdf.

Gibbs, M.H., F.L. Wicker, and A.J. Stewart. 2009. A method for assessing sublethal effects of contaminants in soils to the earthworm, Eisenia fetida. Environmental Toxicology and Chemistry 15(3):360-368 
Gunadi, B., and C.A. Edwards. 2003. The effects of multiple applications of different organic wastes on the growth, fecundity and survival of Eisenia fetida (Savigny) (Lumbricidae). Pedobiologia 47(4):321-329.

Harta judetului Timis (In Romanian). 2015. http:// pe-harta.ro/timis/.

Hund-Rinke, K., T. Achazi, J. Roembke, and D. Warnecke. 2003. Avoidance test with Eisenia fetida as indicator for the habitat function of soils: Soils of a laboratory comparison test. Journal of Soils and Sediments 3(1):7-12.

Hund-Rinke, K., and H. Wiechering. 2001. Earthworm avoidance test for soil assessment. Journal of Soils and Sediments 1(1):15-20.

ISO (International Organization for Standardization). 2008. Soil quality - Avoidance test for determining the quality of soils and effects of chemicals on behavior Part 1: Test with earthworms (Eisenia fetida and Eisenia andrei). ISO 17512-1:2008. http://www.iso.org/iso/ catalogue_detail.htm?csnumber=38402.

Jäntschi, L., and S.D. Bolboacă. 2009. Distribution fitting 2. Pearson-Fisher, Kolmogorov-Smirnov, AndersonDarling, Wilks-Shapiro, Cramer-von-Misses and Barque-Bera statistics. Bulletin of University of Agricultural Sciences and Veterinary Medicine ClujNapoca. Horticulture 66(2):691-697.

Lanno, R., J. Wells, J. Conder, K. Bradham, and N. Basta. 2004. The bioavailability of chemicals in soil for earthworms. Ecotoxicology and Environmental Safety 57(1):39-47.

Loureiro, S., A.M.V.M. Soares, and A.J.A. Nogueira. 2005. Terrestrial avoidance behavior tests as screening tool to assess soil contamination. Environmental Pollution 138(1):121-131.

Lukkari, T.M. 2004. Earthworm Responses to Metal Contamination - Tools for Soil Quality Assessment, $\mathrm{PhD}$ dissertation, University of Jyväskylä, Finland. https://jyx.jyu.fi/dspace/ bitstream/handle/123456789/13135/951391996x. pdf?sequence $=1$.

Murry Jr., A.C., and L.S. Hinckley. 1992. Effect of the earthworm Eisenia fetida on Salmonella enteritidis in horse manure. Bioresource Technology 41(2):97-100.

Natal-da-Luz, T., X. Domene, A. Scheffczyk, and J.P. Sousa. 2009. Earthworm avoidance tests. In Ecotoxicological characterization of waste, Ch. 20, ed. J. Römbke and H. Moser, 191-196. Amsterdam, Netherlands: Springer Science+Business Media LLC, B.V.

Natal-da-Luz, T., R. Ribeiro, and J.P. Sousa. 2004. Avoidance tests with collembola and earthworms as early screening tools for site-specific assessment of polluted soils. Environmental Toxicology and Chemistry 23(9):2188-2193

NIST/SEMATECH. 2015. e-Handbook of Statistical Methods. Chapter 1.3.5.14. Anderson Darling Test. http://www.itl.nist.gov/div898/handbook/eda/ section3/eda35e.htm
OECD (Organisation for Economic Co-operation and Development). 1984. Test No. 207: Earthworm, Acute Toxicity Tests, OECD Guidelines for the Testing of Chemicals, Section 2. Paris: OECD Publishing.

Romeu, J.L. 2000. Anderson-Darling: A Goodness of Fit Test for Small Samples Assumptions. START - Selected Topics in Assurance Related Technologies, 10, 5, 1-6. Rome, NY: Reliability Analysis Center. https://src. alionscience.com/pdf/A_DTest.pdf.

Schimel, J.P., and J. Bennett. 2004. Nitrogen mineralization: Challenges of a changing paradigm. Ecology 85:591-602.

Shin, K.H., and K.W. Kim. 2001. Ecotoxicity monitoring of hydrocarbon-contaminated soil using earthworm (Eisenia fetida). Environmental Monitoring and Assessment 70(1-2):93-103.

Stephenson, G.L., A. Kaushik, N.K. Kaushik, K.R Solomon, T. Steele, and R.P. Scroggins. 1998. Use of an avoidance-response test to assess the toxicity of contaminated soils to earthworms. In Advances in Earthworm Ecotoxicology, ed. S.C. Sheppard, J.D Bembridge, M. Holmstrup, and L. Posthuma, 67-81. Pensacola, FL: Society of Environmental Toxicology and Chemistry (SETAC) Press.

Tărău, D. 2013. Cadrul natural și particularitățile zonale ale județul Timiș (In Romanian). In OSPA (Oficiul pentru Studii Pedologice si Agrochimice) Timișoara. http://www.ospatimisoara.ro/Cadrul\%20natural\%20 Timis\%20(tabelul\%201).pdf.

Udovic, M., and D. Lestan. 2010. Eisenia fetida avoidance behavior as a tool for assessing the efficiency of remediation of $\mathrm{Pb}, \mathrm{Zn}$ and $\mathrm{Cd}$ polluted soil Environmental Pollution 158(8):2766-2772.

Wang, Y., T.Z. Cang, R. Yu, L. Chen, C. Wu, and Q. Wang 2012. Comparative acute toxicity of twenty-fou insecticides to earthworm Eisenia fetida. Ecotoxicology and Environmental Safety 79:122-128.

Yeardley, R.B., J.M. Lazorchak, and L.C. Gast. 1996. The potential of earthworm avoidance test for evaluation of hazardous waste sites. Environmental Toxicology and Chemistry 15(9):1532-1537.

Zhou, S., C. Duan, H. Fu,Y. Chen, X. Wang, and Z.Yu. 2007. Toxicity assessment for chlorpyrifos-contaminated soil with three different earthworm test methods. Journal of Environmental Sciences 19(7):854-858. 